\title{
PROGRAMAS DE ENSINO E PLANOS DE EDUCAÇÃO NA ESCOLA NORMAL DA FEIRA DE SANTANA, 1927 - 1935
}

\author{
Bruna Santana da Silva ${ }^{1}$; Ione Celeste Jesus de Sousa ${ }^{2}$ \\ 1. Bolsista PIBIC/CNPq, Graduanda em Licenciatura em História, Universidade Estadual de Feira de Santana, e- \\ mail: bssilva.fsa@gmail.com \\ 2. Orientador, Departamento de Ciências Humanas e Filosofia, Universidade Estadual de Feira de Santana, e-mail: \\ beltrano@provedor.br
}

PALAVRAS-CHAVE: Escola Normal; Feira de Santana; Plano de Ensino.

\section{INTRODUÇÃO}

A presente proposta de trabalho, que se insere no campo da História Cultural da Educação, tem como foco o estudo da Escola Normal da Feira de Santana durante os anos de 1927 a 1935, em especial, a análise das mudanças que ocorreram no Programa de ensino na unidade escolar e os desdobramentos dos decretos de lei e planos de mudança para a educação nacional, que estraram em vigor ao longo desse período. Nas brechas da historiografia e a contribuição que o seguinte trabalho se propõe, é possível partir de uma análise trilhando justamente esse caminho, de enxergar justamente os pontos e caminhos dessa historiografia da educação no município e entender de que forma foram constituídos os Programas de Ensino dentro da Escola Normal de Feira de Santana ao ponto de atender as demandas da população na época. Lançando mão de outras obras que buscam evidenciar as características da Escola Normal dialogando assim com outros historiadores, partindo de uma necessidade e uma nova perspectiva para a educação no Brasil. A historiografia em volta da História da Educação ainda é muito recente, porém, já existem grandes referencias para o seu estudo, como os citados anteriormente, e novos trabalhos sendo produzidos nas academias no país. Essa pesquisa buscou cumprir a função de contribuir para uma história da própria cidade de Feira de Santana, partindo de uma abordagem local e regional; lançando mão de um dialogo acerca de outras obras e projetos que buscam evidenciar pontos cruciais do ensino na Escola Normal da Feira de Santana, trazendo esses pontos através de uma cultura escolar do município.

\section{MATERIAL E MÉTODOS OU METODOLOGIA (ou equivalente)}

A grande parte da documentação disponível para a pesquisa sobre a Escola Normal da Feira de Santana se encontram, nas dependências dos prédios do Instituto de Ensino Gastão Guimarães, constando de um acervo composto por atas, livros de escrituração, cadernetas escolares das disciplinas discutidas na proposta desta pesquisa, livros referentes a toda burocracia escolar; desde visitantes a portarias; não pode ser esquecido o jornal de maior circulação no município naquele período, o "Folha do Norte", fundado em 1909, contém em seus periódicos, os decretos de lei lançados ao longo do período analisado bem como, noticias acerca do cotidiano da própria Escola Normal. 


\section{RESULTADOS E/OU DISCUSSÃO (ou Análise e discussão dos resultados)}

Quanto aos resultados esperados, todos estavam relacionados a partir do alcance dos objetivos citados no plano de trabalho. Contudo, apesar da impossibilidade de acesso as fontes, foram possíveis a partir da análise de documentos históricos entender qual a dinâmica que a Escola Normal deveria seguir. A Lei no 2064 de 31 de março de 1924, o Regulamento das Escolas Normaes Primarias apresenta ao longo de seus artigos os pontos basilares para a formação de futuros professores nos Institutos de Ensino. Com a Escola Normal de Feira de Santana isso não foi diferente, seguindo as propostas educacionais regulamentadas e aprovadas pelo Governo do Estado do período, teve sua formação norteada a partir dos interesses daqueles que detinham de poder.

A partir do catálogo elaborado por Oliveira (2011) com o levantamento das principais publicações do Jornal Folha do Norte a respeito dos acontecimentos em volta da Escola Normal de Feira de Santana no período proposto, foi possível entender um pouco da rotina escolar, a partir dos periódicos que apresentavam as mais diversas notícias sobre o cotidiano da Escola Normal de Feira de Santana, desde padronização dos horários das aulas, fincando o $1^{\circ}$ turno das 08:00 horas as 11:45 e o $2^{\circ}$ turno das 13:00 horas as 16:45 com intervalos para o descanso da criança, no turno matutino das 10:00 as 10:30 e no período vespertino das 15:00 as 15:30; aperfeiçoamento das praticas docentes a parti de estágios, com a determinação da pratica dos alunos do $5^{\circ}$ ano normal (ou $2^{\circ}$ pedagógico) nas Escolas Elementares. Bem como a inauguração da Escola Normal, esta conclamada pelo Periódico, que acompanhou suas mudanças e adaptações.

\begin{tabular}{|c|c|c|c|c|}
\hline $28 / 05 / 1927$ & 933 & 01 & 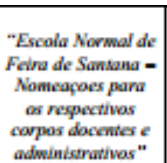 & \begin{tabular}{|c|} 
Registro de \\
convite público \\
para \\
inugguraçlo da \\
Escola Normal \\
de Feira em \\
1927.
\end{tabular} \\
\hline $04 / 06 / 1927$ & 934 & ol & 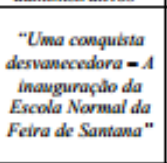 & $\begin{array}{l}\text { Registro } \\
\text { descritivo de } \\
\text { solenidade } \\
\text { inaugural da } \\
\text { Escola Normal } \\
\text { de Feira, em } \\
1927 .\end{array}$ \\
\hline $11 / 06 / 1927$ & 935 & 01 & "Escola Normal" & $\begin{array}{c}\text { Deliberaçoes } \\
\text { sobre } \\
\text { funcionamento } \\
\text { da Escola } \\
\text { Normal de Feira } \\
\text { em } 1927 \text {. } \\
\end{array}$ \\
\hline $11 / 06 / 1927$ & 935 & 01 & $\begin{array}{l}\text { "Nomeaceles para } \\
\text { o Grupo Escolar } \\
\text { Dr. L. J. Seabra" }\end{array}$ & $\begin{array}{c}\text { Deliberaçoes } \\
\text { sobre } \\
\text { funcionamento } \\
\text { da Escola } \\
\text { Aneva a Escola } \\
\text { Normal de Feira } \\
\text { em } 1927 \text {. }\end{array}$ \\
\hline $09 / 07 / 1927$ & 939 & 03 & $\begin{array}{c}\text { "Escola Narmal da } \\
\text { Feira - A } \\
\text { comemovapdo do } \\
02 \text { de Julho" }\end{array}$ & $\begin{array}{c}\text { Registro } \\
\text { descritivo de } \\
\text { festa escolar ma } \\
\text { Escola Normal } \\
\text { de Feira em } \\
1927 .\end{array}$ \\
\hline $16 \times 07 / 1927$ & 940 & 01 & $\begin{array}{l}\text { "Escola Normal de } \\
\text { Feira de Santana" }\end{array}$ & \begin{tabular}{|c|} 
Registro de \\
solenidade \\
festiva na \\
Escola Normal \\
de Feira, 1927.
\end{tabular} \\
\hline
\end{tabular}

Figura 1: Levantamento realizado por Oliveira a cerca das mudanças ocorridas na Escola Normal de Feira de Santana registradas no Jornal Folha do Norte (1927) 


\section{CONSIDERAÇÕES FINAIS (ou Conclusão)}

Apesar da própria limitação do tempo e acesso ao material referente à pesquisa, o que impossibilitou o andamento deste trabalho, acredito ter contribuído para o amadurecimento das discussões no que toca a História da Educação na cidade de Feira de Santana dentro grupo de estudo HISTEICE, entender como o estudo da Escola Normal a partir da ótica da modernização do município pode nos levar a compreender o papel da educação na formação dos professores e futuros alunos daquela instituição.

\section{REFERÊNCIAS}

ALMEIDA, Camila da Silva. Escola normal da Feira de Santana: práticas da gratuidade e caixa escolar, 1927-1954. 2013. Disponível em: <http://anpuhba.org/wpcontent/uploads/2013/12/Camila-Almeida-ST-16.pdf>. Acesso em: 03 abr. 2015

BARCELOS, Ana Regina Ferreira de; MELO, Marilândes Mól Ribeiro de. As escolas normais no Brasil: do império a república. Revista Percursos, Florianopólis, v. 12, n. 1, p.233-235, jul. 2011.

CRUZ, Antonio R. S. da. Mestres e mestras para o Sertão: criação e funcionamento da Escola Normal de Feira de Santana. FSA: Sitientibus, no 31, jul/ dez 2004, pp.143-168;

OLIVEIRA, Daiane da Silva. Fontes para uma história da educação em Feira de Santana - catálogo do jornal Folha do Norte - 1920/1960. PPPG/UEFS-BA: 2011.

SOUSA, Ione C. J. de. Garotas tricolores, Deusas fardadas: as normalistas em Feira de Santana. Dissertação de Mestrado em História Social. PEPGHS/PUC-SP: 1999. 